\title{
Bronchopulmonary anastomoses in sickle-cell anaemia
}

\author{
DONALD HEATH AND IAN McKIM THOMPSON \\ From the Departments of Pathology, University of Liverpool, and the East Birmingham Hospital
}

Histological details are given of bronchopulmonary anastomoses in a patient who died suddenly and was known to have sickle-cell anaemia.

Histological studies of a recent case of sickle-cell anaemia provided an opportunity to elucidate the microanatomy of bronchopulmonary anastomoses. These are often referred to in papers dealing with disturbance of the pulmonary circulation, but their detailed structure has rarely been described.

\section{CASE REPORT}

The patient was a negro man aged 28 years who collapsed suddenly and died in the street following a vague history of pain in the chest. In view of the sudden unexpected nature of the death H.M. Coroner was informed and ordered a necropsy to be performed. Subsequent investigations revealed that the man had experienced similar pain in the abdomen seven years before. It further transpired that he had previously suffered a spontaneous peripheral detachment of the left retina. Operation for this was carried out successfully. The diagnosis of sickle-cell anaemia had been queried and was confirmed by electrophoresis of haemolysed red cells on a cellulose acetate strip. The ' $S$ ' and ' $C$ ' bands were plainly visible and typical. Subsequently he developed further ophthalmological complications in the form of retinal detachments and cataract which resulted in virtual blindness.

NECROPSY FINDINGS The salient features were that on cut section the lungs presented a remarkable appearance of widespread and severe thrombosis of the pulmonary arteries. The thrombus appeared as solid dark red cords which protruded from most of the pulmonary arteries, ranging in size from lobar vessels down to small elastic pulmonary arteries.

The heart, devoid of fat, weighed $275 \mathrm{~g}$. The right ventricle weighed $65 \mathrm{~g}$. (upper limit of normal), the left ventricle $175 \mathrm{~g}$. (normal), and the atria $35 \mathrm{~g}$. The ratio of left to right ventricular weight was $2 \cdot 6$, which is normal and not indicative of isolated right ventricular hypertrophy. The heart valves were normal in structure and circumference. There was no coronary thrombosis. The spleen (50 g.) was small, shrunken, and fibrotic.
It was brownish in colour due to deposition of haemosiderin. The other organs were congested but showed no structural abnormality. Death was considered to be due to widespread pulmonary thrombosis associated with sickle-cell anaemia.

Pulmonary vascular pathology There was wide⿳亠丷厂 spread occlusion of the elastic pulmonary arteries $(>1,000 \mu$ in external diameter) by recent, organs izing, and organized thrombi (Fig 1). In many of these vessels large clumps of thrombus had undere gone organization with the formation of excentrio nodules of fibrous and fibroelastic tissue closel adherent to the intima (Fig. 1). In other arterieg there was extensive recanalization with the forma tion of colander-like lesions, large patent channelst

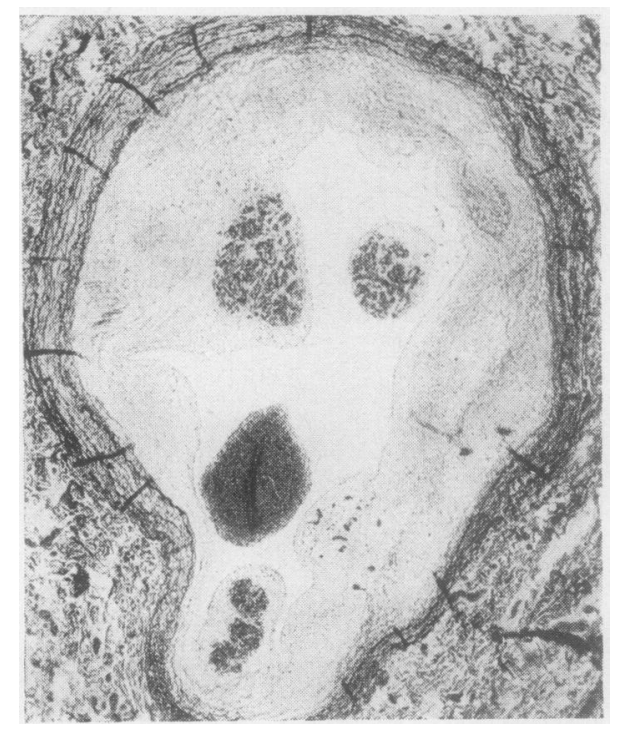

FIG. 1. Transverse section of an elastic pulmonary arter showing clumps of recent thrombus with evidence कo organization and incorporation into a thick fibrous linin to the vessel. Other pulmonary arteries were totaly occluded by this process. (Elastic/Van Gieson, $\times 25$.) 
being surrounded by thick septa of fibrous tissue (Fig. 2). A few elastic pulmonary arteries contained bands and webs, thinner strands of fibroelastic tissue being stretched across the vascular lumen; these webs clearly represented a more advanced stage of organization of the colanderlike lesions.

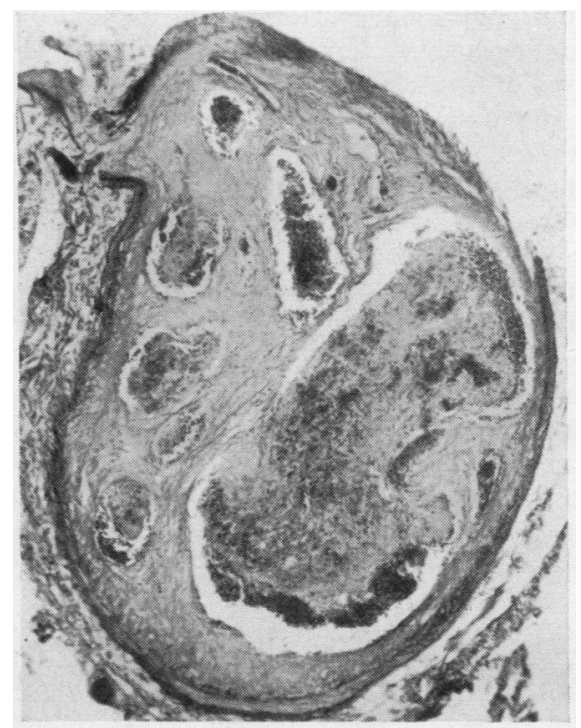

FIG. 2. Transverse section of a muscular pulmonary artery showing a classical 'colander lesion' due to recanalization of organized thrombus. The underlying media shows atrophic change secondary to the thrombus occluding the vessel. (Elastic/Van Gieson, $\times 65$.)

Within the organized thrombus were numerous blood capillaries (Fig. 3) which predominated in the zone immediately subjacent to the internal elastic lamina. Some of these thin-walled vessels were much larger, and a few of them had a distinct muscular media sandwiched between two elastic laminae. In many areas the media underlying organized thrombus had undergone atrophy with loss of musculoelastic tissue so that the medial thickness was reduced from something of the order of $250 \mu$ down to a thin elastic coat about $30 \mu$ thick. In these areas there was disruption of the elastic fibrils of the media, and many of them appeared frayed (Fig. 3). Small capillary vessels coursed through these areas of disrupted media (Fig. 4) and communicated with branches of prominent bronchial arteries which surrounded the elastic pulmonary arteries forming their vasa vasorum. These were recognized by their thick intimal coat of longitudinal muscle, a media taking up the Van Gieson stain comparatively faintly, a distinct thick internal elastic lamina, and a virtually absent external elastic lamina (Fig. 5). These bronchopulmonary anastomoses are described in detail below.

The 'muscular pulmonary arteries' (between $100 \mu$ and $1,000 \mu$ in external diameter) were thinwalled and showed none of the structural features associated with pulmonary hypertension. Some of them contained organizing thrombus. The pulmonary arterioles had a coat consisting of a single elastic lamina, and there was no evidence of muscularization of this wall such as occurs in pulmonary hypentension. The pulmonary capillary bed was prominent due to the distension of capillaries by tactoids and microthrombi. The pulmonary veins showed minimal intimal fibrosis consistent with normal age change.

Bronchopulmonary anastomoses The microscopic structure of a typical acquired bronchopulmonary anastomosis (A) is shown in Figures 5 to 8. In

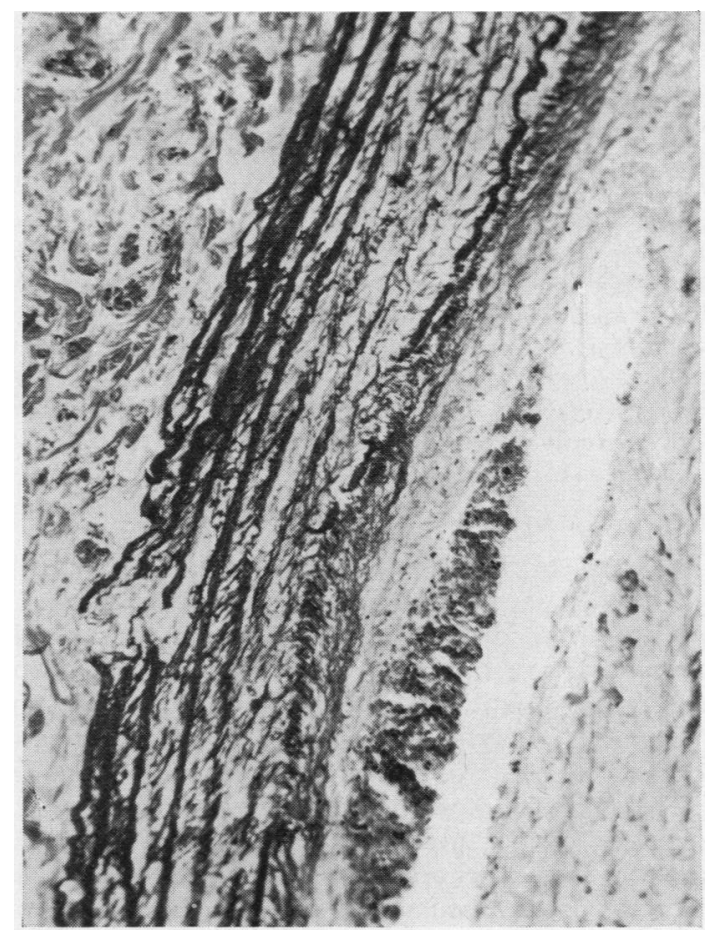

FIG. 3. Part of a transverse section of an elastic pulmonary artery. To the right the lumen is occluded by organized thrombus which contains a recanalization channel. The media shows early fragmentation of its elastic laminae. (Elastic/Van Gieson, $\times 115$.) 


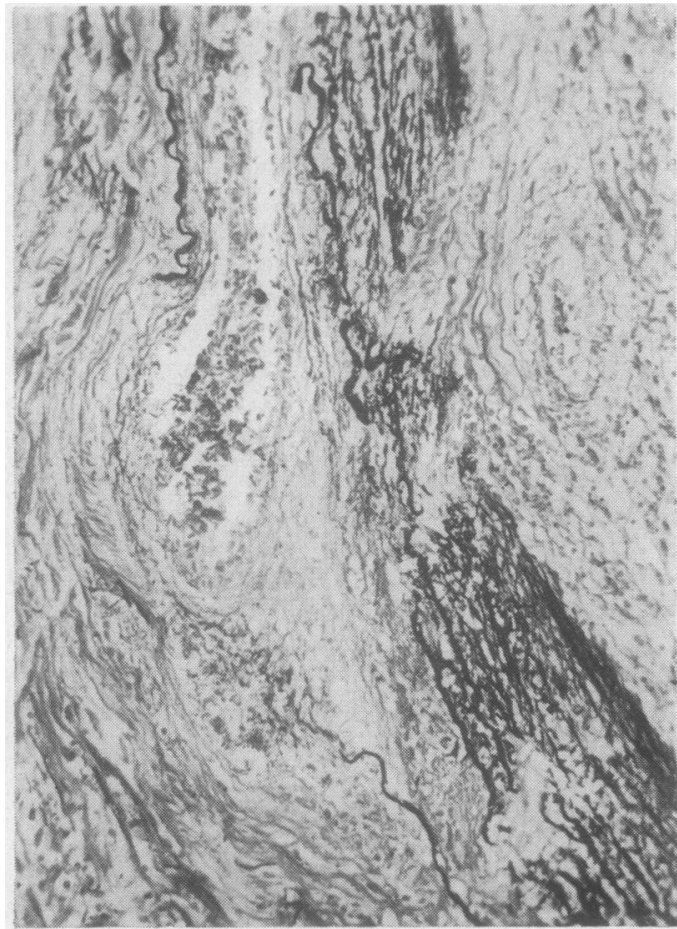

FIG. 4. Part of a transverse section of an elastic pulmonary artery. To the right the lumen is occluded by organized thrombus which contains recanalization channels. The underlying media shows considerable fragmentation of elastic fibrils which leave ragged edges. There is also much separation of elastic fibrils. Between these are situated thin-walled vascular channels which communicate with both the recanalization channels in the organized thrombus and with thin-walled vessels in the adventitia. (Elastic/Van Gieson, $\times 115$.)

Fig. 5 the entire anastomosis is shown; fortuitously it has been sectioned longitudinally throughout its entirety. The disrupted media of an elastic pulmonary artery shows the fragmentation and separation of elastic laminae previously referred to. It runs obliquely downwards from the upper right to the lower left of the picture. Above and to its left the lumen of the elastic pulmonary antery is occluded by organized thrombus which, however, contains small recanalization channels. There is a break in the media with ragged edges. One of the recanalization channels has dilated and has broken through the fragmented media to pass vertically downwards to effect communication with a bronchial artery running obliquely upwards and parallel to the elastic pulmonary artery. Figure 6 shows the break in the media of the pul- monary artery and the exit of the dilated recanal- $\overrightarrow{\bar{s}}$ ization channel at higher magnification. The $\frac{\overrightarrow{0}}{0}$ ragged edges of this exit vessel with fragmentation 듬 and disruption of elastic laminae shows this ves- $\frac{\bar{m}}{\bar{T}}$ sel to have been acquired as a result of a disease $\overparen{D}$ process and contrasts sharply with the well-

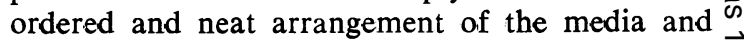
its elastic laminae at the normal origin of a $\vec{\circ}$ muscular pulmonary artery from a parent elastic $\overrightarrow{\vec{\omega}}$ pulmonary artery. This connecting vessel (Fig. 7) consists of muscle fibres but is virtually devoid $\overrightarrow{\vec{r}}$ of elastic tissue. It has the structure of neither a pulmonary nor a bronchial artery. It leads into a blood vessel with the characteristic histological iv structure of a systemic artery with a well-defined $\mathbb{N}_{N}$ media of circular muscle and an internal elastic 0 lamina, although the external elastic lamina is virtually absent (Fig. 8). This vessel is a bronchial $\bar{z}$ artery and completes the bronchopulmonary anastomosis.

Another such anastomosis (B) is shown in $\vec{\oplus}$ Figures 9 to 11. In Fig. 9 the organized thrombus of which occludes the elastic pulmonary artery is shown to the upper right. Small recanalization channels are visible in this mass. One of these

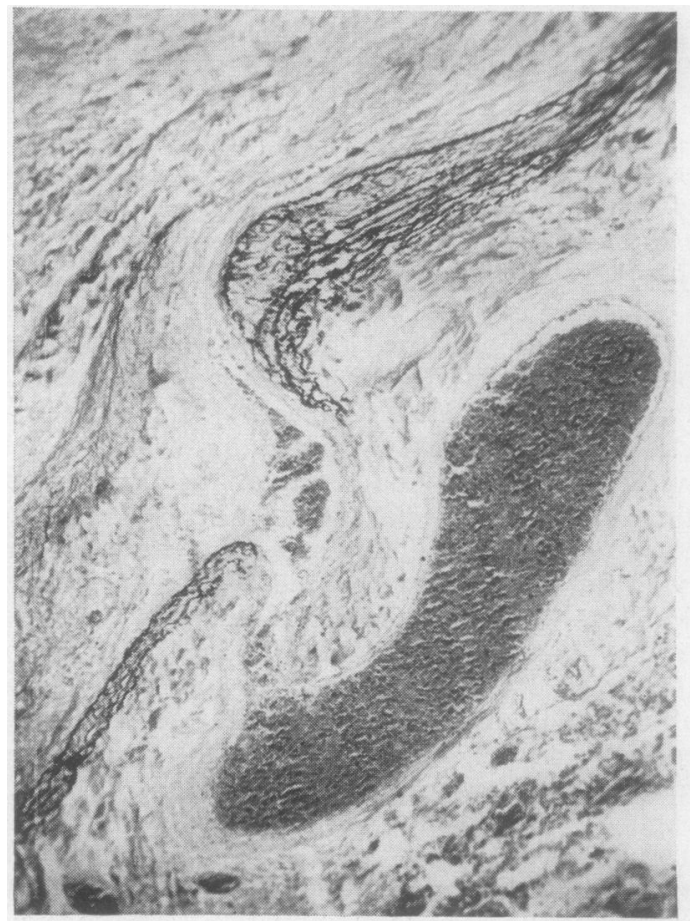

FIG. 5. The entire bronchopulmonary anastomosis $(A) \stackrel{0}{0}$ described in the text. (Elastic/Van Gieson, $\times 76$. 


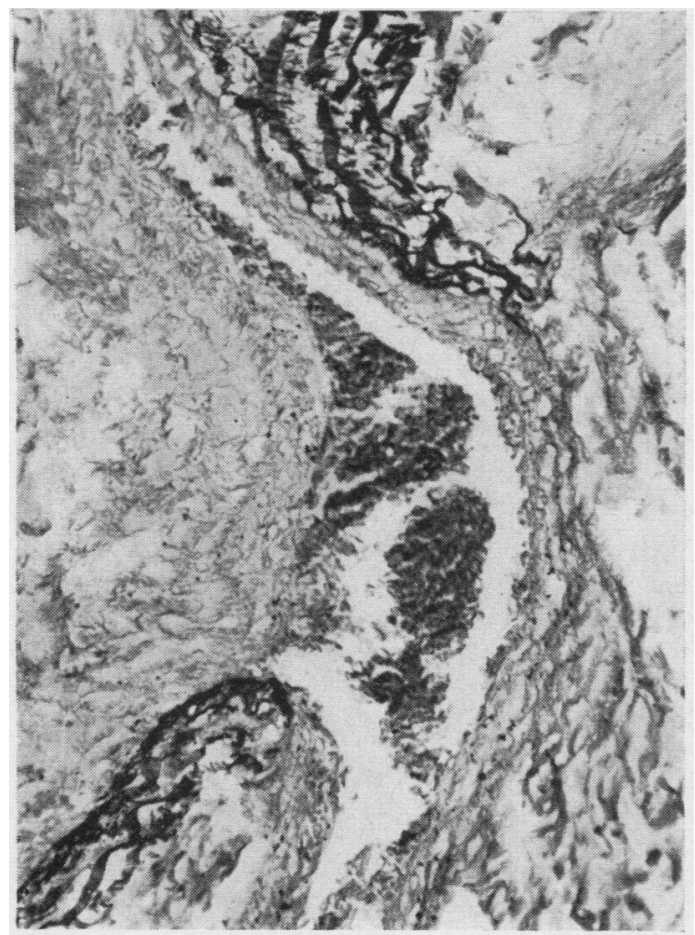

FIG. 6. The first part of the exit channel which appears to have broken through the ragged mexia. (Elastic/Van Gieson, $\times 150$.)

FIG. 7. The second part of the exit channel which connects with the blood vessel in the adventitia of the elastic pulmonary artery. (Elastic/Van Gieson, $\times 150$.)

FIG. 8. The bronchial artery completing the bronchopulmonary anastomosis. (Elastic/Van Gieson, $\times 150$.)

FIG. 6
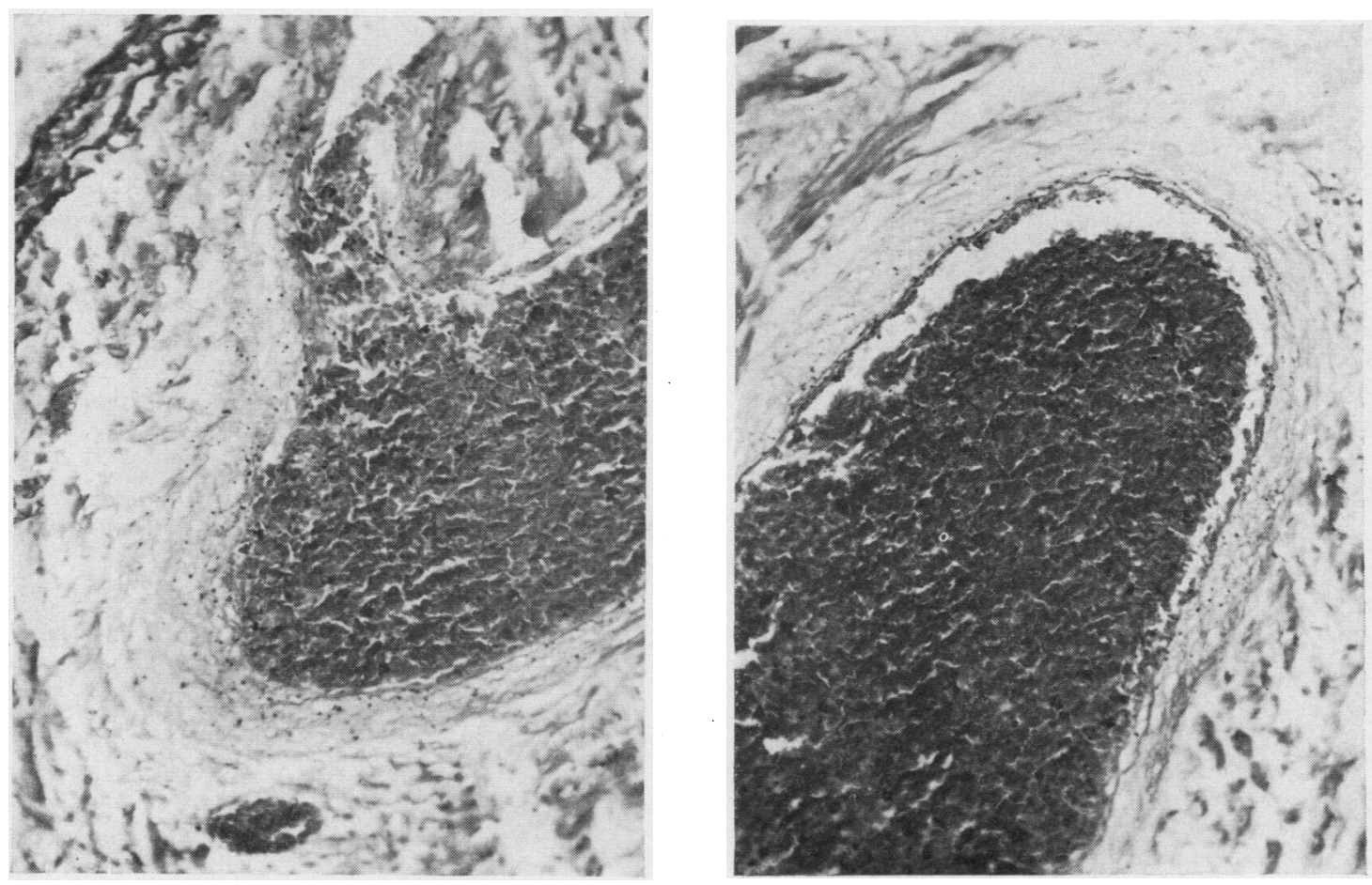

FIG. 7

FIG. 8 


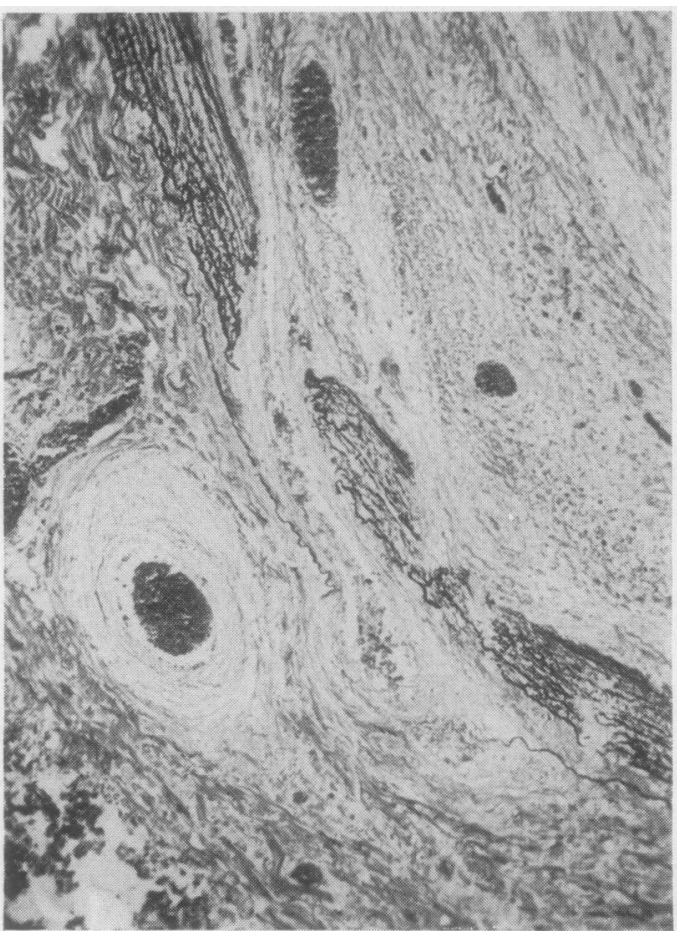

FIG. 9

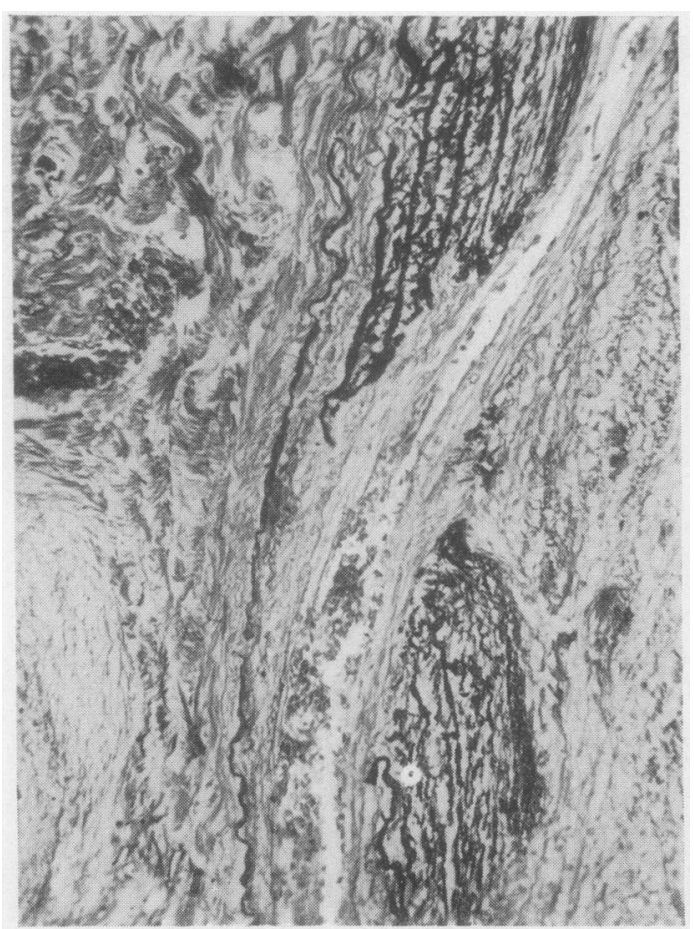

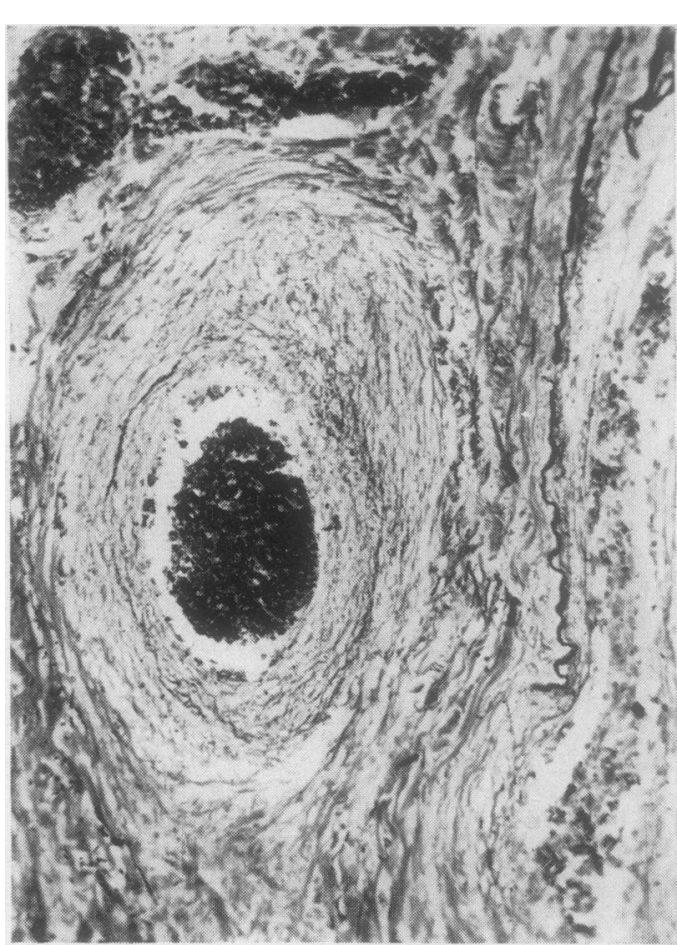

FIG. 11

FIG. 9. The entire bronchopulmonary anastomosis $(B)$ described in the text. (Elastic/Van Gieson, $\times 115$.$) 은$ FIG. 10. The exit channel which has broken through the ragged media. (Elastic/Van Gieson, $\times 115$.)

FIG. 11. The fibrosed vessel in the adventitia completing the bronchopulmonary anastomosis. (Elastic/Van Gieson $\times 115$.) 
channels passes down vertically to break through the media of the pulmonary artery which forms an arc traversing the upper right portion of the figure. The elastic fibrils of the media show extensive fragmentation and separation, and the edges are ragged in striking contrast to the orderly arrangement of the emergence of a normal branch of an elastic pulmonary artery (Fig. 10). This thinwalled vascular channel communicates with an artery in the adventitia of the elastic pulmonary artery (Fig. 11). In this case the structure of the artery completing the bronchopulmonary anastomosis is distorted, considerable fibrous change affecting both its media and intima (Fig. 11). However, its situation leads one to conclude that, as in the first anastomosis, it is certainly bronchial in nature.

\section{DISCUSSION}

The cause of pulmonary thrombosis in sickle-cell anaemia, which particularly affected the elastic arteries of the lung in this patient, is a genetically determined defect in the chemical constitution of the haemoglobin. Human haemoglobin has two pairs of chains, designated $\alpha$ - and $\beta$-. During oxygenation the spatial configuration of these chains alters such that the $\beta$-chains move together about $7 \AA$. Sickle-cell haemoglobin differs from normal haemoglobin by the substitution of valine for glutamic acid at the sixth position in the $\beta$-chain. This substitution alters the configuration of the terminal residues of the $\beta$-chain such that on deoxygenation it interacts at a complementary site on an adjacent $\alpha$-chain. This interaction results in molecular stacking with the production of tactoids and a rigid deformity of erythrocytes.

The widespread thrombosis in the elastic pulmonary arteries must impede pulmonary flow and elevate pulmonary vascular resistance. This in turn leads to right ventricular hypertrophy and affords adequate explanation of the development of cor pulmonale in sickle-cell anaemia. The pulmonary arteries distal to the organized thrombi are clearly not subjected to an elevated pressure and, as has been noted, remain thin-walled.

This case is of interest in demonstrating the mode of development of bronchopulmonary anastomoses in sickle-cell anaemia, which is most likely the same in any disease associated with chronic pulmonary thrombosis. Such anastomoses are so frequently referred to in papers dealing with the patho-physiology of the pulmonary circulation that it is salutary to recognize how rarely the morphology of these vascular con- nexions has been described in detail. Wintrobe (1961), for example, notes that unsaturation of systemic arterial blood is comparatively frequent in sickle-cell anaemia and suggests that this is due principally to intrapulmonary shunting of blood. He does not, however, describe the form or mode of development of such shunts.

Bronchopulmonary anastomses occur in normal lungs where they are found in the walls of bronchi and in the pleura supplied by bronchial arteries (Wagenvoort, Heath, and Edwards, 1964). In adults they are rare and appear to be branches of bronchial arteries since their structure is much more like that of a bronchial than a pulmonary artery. In this respect they show longitudinal muscle in the intima. These anastomotic vessels are usually narrow and tortuous, although wide straight forms may be found. They run a short course of up to $300 \mu$ in length and probably have little functional significance in the lung of the adult free of cardiopulmonary disease. Bronchopulmonary anastomoses are common in the foetus and infant where they form wide straight vessels. In that part of their course where they run to join radicles of the pulmonary arterial tree, they have the typical structure of a pulmonary artery. All normal bronchopulmonary anastomoses thus consist of well-formed arteries with an orderly arrangement of muscle coat and elastic laminae.

In striking contrast to these is the acquired form of bronchopulmonary anastomosis which has the ragged appearance described in detail above. Anastomotic vessels of virtually identical structure to those we report here have been described by Cudkowicz and Armstrong (1953) in cases of emphysema. They found that, in severe examples of this disease, hypertrophied bronchial arteries sometimes communicated with fibrosed pulmonary arteries lying in apposition to damaged bronchi. The vascular connexions were rarely larger than $100 \mu$ in diameter, and seemed to be branches of bronchial vasa vasorum which penetrated the media of the large elastic pulmonary arteries to recanalize organized thrombus occluding the lumen of the pulmonary artery. Bronchopulmonary anastomoses of identical type may be found in those cases of bronchiectasis associated with thrombosis of elastic pulmonary arteries (Wagenvoort et al., 1964).

These are different in structure from the common type of bronchopulmonary anastomosis which has been described in bronchiectasis by Liebow, Hales, and Lindskog (1949). These are found adjacent to bronchiectatic sacs alongside bronchi of the fourth order of branching. The bronchial 
arteries spiral before communicating with the pulmonary arterial tree, the coils being tight, wide, and numerous. The bronchial artery is of the same size or slightly smaller than the pulmonary artery with which it connects. They are of the acquired variety and appear to develop from capillaries of granulation tissue which is derived from both bronchial and pulmonary circulations.

The function of such bronchopulmonary anastomoses and the direction of flow of blood through them are uncertain. They may provide a second systemic source of blood to enter the peripheral pulmonary arterial tree deprived of a normal flow of blood by the widespread thrombosis. Alternatively, it is possible that the flow of blood takes place in the opposite direction, that is from elastic pulmonary arteries to bronchial arteries, providing a decompression valve from the proximal portions of the pulmonary arterial tree subjected to hypertension.
Here we report only the bronchopulmonarye anastomoses and the pulmonary thromboses, buto it is worth mentioning that retinal complicationso and pulmonary thromboses are not uncommon in haemoglobin sickle-cell disease.

We wish to thank Mr. George Billington, H.M Coroner to the City of Birmingham, for permission to report this case.

\section{REFERENCES}

Cudkowicz, L., and Armstrong, J. B. (1953). The bronchial arteries in pulmonary emphysema. Thorax, $8,46$.

Liebow, A. A., Hales, M. R., and Lindskog, G. E. (1949). Enlarge-N ment of the bronchial arteries and their anastomoses with theo pulmonary arteries in bronchiectasis. Amer. J. Path., 25, 211.

Wagenvoort, C. A., Heath, D., and Edwards, J. E. (1964). ThePathology of the Pulmonary Vasculature. Charles C. Thomas Springfield, Illinois.

Wintrobe, M. M. (1961). Clinical Hematology, 5th ed., p. 673ล̄ Lea and Febiger, Philadelphia. 